\title{
Concepções dos alunos sobre os tensionamentos étnico-raciais na escola e na sociedade
}

\author{
Students' conceptions of ethnic-racial tensions in school and society
}

Fernanda Wanderer*
Mônica Nunes*

Resumo

Este artigo apresenta resultados de uma pesquisa desenvolvida com o propósito de examinar enunciações de alunos dos anos finais do ensino fundamental de uma escola pública de Estrela, RS, um município de colonização alemã, sobre os marcadores étnico-raciais que operam na escola e na sociedade. Essas questões se potencializaram, na atualidade, com a imigração haitiana presente na cidade. Os aportes teóricos que sustentam o estudo advêm de discussões contemporâneas sobre raça e etnia, como os trabalhos de Meyer (2011), Silva (2005, 2017) e Gomes (2003). O material de pesquisa escrutinado é composto por observações de aulas e registros de atividades pedagógicas postas em ação em uma turma do $8^{\circ}$ ano do ensino fundamental. A análise mostrou a existência de práticas discriminatórias na cidade onde vivem os discentes, em especial, em relação aos negros. Contudo, os estudantes afirmam que essas práticas não se fazem presentes na escola. Além disso, os alunos negros não se identificam com sua negritude, autodenominando-se de "morenos" ou "meio morenos", mostrando que o pertencimento étnico-racial se constitui em um processo envolto em tensões que frequentemente geram negação ou rejeição ao sentimento de pertença a um determinado grupo.

Palavras-chave: Alunos. Escola. Marcadores étnico-raciais.

\section{Abstract}

This article presents the results of a research carried out with the purpose of examining the statements of students from the Final Years of Elementary School in a public school in Estrela, RS, a municipality of German colonization, about ethnic and racial markers operating in school and society. These questions are potentiated, at present, with Haitian immigration in this city. The theoretical contributions that support the study come from contemporary discussions about race and ethnicity, such as Meyer $(2011)$, Silva $(2005,2017)$ and Gomes (2003). The research material scrutinized consists of observations of classes and records of pedagogical activities put into action in a class of the 8th Year of Elementary Education. The analysis showed the existence of discriminatory practices in the city where the students live, especially in relation to blacks. On the other hand, the students affirm that these practices are not present in the school. In addition, black students do not identify with their blackness, calling themselves "morenos" or "half brown," showing that ethnic-racial belonging constitutes a process surrounded by tensions that often generate denial or rejection to the feeling of belonging to a particular group.

Keywords: Students. School. Ethnic-racial markers.

$$
\begin{gathered}
\text { Recebido em 13/06/2018 - Aprovado em 23/11/2018 } \\
\text { http://dx.doi.org/10.5335/rep.v26i2.7706 }
\end{gathered}
$$

Doutora em Educação pela Universidade do Vale do Rio dos Sinos. Professora do Programa de Pós-Graduação em Educação da Universidade Federal do Rio Grande do Sul, Brasil. E-mail: fernandawanderer@gmail.com

** Mestre em Educação pela Universidade Federal do Rio Grande do Sul. Coordenadora pedagógica do Colégio Martin Luther e professora de História de Ensino Fundamental II no Colégio Sinodal Gustavo Adolfo, Brasil. E-mail: monicanunes150@gmail.com 


\section{Introdução}

Este artigo problematiza questões vinculadas aos tensionamentos étnico-raciais na área da Educação. As reflexões apresentadas emergem de uma pesquisa desenvolvida com o propósito de examinar enunciações de alunos dos anos finais do ensino fundamental de uma escola pública de Estrela, RS, um município de colonização alemã, sobre os marcadores étnico-raciais que operam na escola e na sociedade, em especial as relações que se estabelecem entre brancos e negros, as quais se potencializaram, na atualidade, com a chegada dos haitianos na referida cidade.

Inicialmente, consideramos pertinente destacar o sentido que estamos atribuindo a raça e etnia. De acordo com Meyer (2011), a noção de raça passa a ser desenvolvida no período da colonização, apresentando fortes vínculos com a área biológica. Já o termo etnia, utilizado no período posterior à Segunda Guerra Mundial, vincula-se às características produzidas por um determinado grupo e passa a ser usado para enfatizar que os sujeitos se constituem por meio de fenômenos históricos e sociais, afastando-se do viés biológico. A autora alerta que etnia, referindo-se às características culturais de um povo, também é um termo colocado sob rasura, imbricado de conflitos e relações de poder. Esses conceitos são, assim, “[...] construções que se dão no interior dos processos sociais, resultados de uma relação de poder entre forças que se exercem tanto para a dominação como para a resistência" (MEYER, 2011, p. 47). Cientes de que essas definições estão carregadas de tensionamentos, utilizamos, ao longo do texto, as expressões "raça-etnia" ou "étnico-racial", acompanhando Munanga (1999) e Silva (2017).

As discussões sobre raça-etnia envolvem também reflexões acerca da branquitude (SCHUCMAN, 2014; SANTOS, 2018; MEINERZ; PEREIRA, 2018). Para Schucman (2014), a branquitude pode ser considerada como uma posição em que sujeitos brancos são privilegiados na obtenção de recursos materiais e simbólicos em relação a outros grupos racializados, como os negros. Em sua pesquisa, foram examinadas falas de brancos paulistanos de diferentes classes sociais, para compreender como o poder branco atua no cotidiano dos sujeitos. Os resultados indicam que os brancos reconhecem que são privilegiados em relação aos outros grupos raciais, mas não se responsabilizam por isso, eximindo-se da responsabilidade moral e social que envolve as relações étnico-raciais.

Apoiando-se em Schucman, Meinerz e Pereira (2018) destacam que nossa sociedade é caracterizada por uma grande mistura racial, mas segue pautada pela 
branquitude como norma social. Para as autoras, “[...] branquitude se refere a um lugar de poder, de vantagens e de acesso a privilégios nas sociedades estruturadas racialmente, onde um grupo racial tem o poder de governar, elaborar e reelaborar políticas sociais, econômicas e culturais" (MEINERZ; PEREIRA, 2018, p. 170). Assim, sujeitos brancos passam a ser posicionados como superiores, tendo seus saberes, seus modos de ser e de viver como padrões.

$\mathrm{Na}$ esteira dessas reflexões, Gomes (2003) destaca que as diferenças entre negros e brancos foram construídas por processos culturais e sociais, estabelecendo-se como uma forma de classificação e hierarquização dos sujeitos. Essas hierarquizações se materializam nas desigualdades econômicas, sociais e educacionais presentes em nosso país, nas quais se percebe que alguns grupos (como os negros) estão em situações de desvantagens em relação aos brancos. Nesse sentido, segundo o Instituto de Pesquisa Econômica Aplicada (Ipea), em 1997, 57,7\% dos negros brasileiros eram pobres. Dez anos depois, eram 41,7\%. Entre os brancos, o percentual caiu de $28,7 \%$ para $19,7 \%$ no mesmo período. Ademais, fica evidente a desigualdade econômica que se manifesta também na disparidade no acesso à educação formal. Se olharmos para os dados sobre o analfabetismo, por exemplo, podemos perceber que as taxas são maiores para negros do que para brancos (IPEA, 2017).

Este quadro de grandes desigualdades mobilizou, nos últimos anos, um conjunto de medidas e ações que passaram a ser efetivadas em áreas como a Educação. Entre elas, de acordo com Silva (2017), podemos mencionar políticas como as Diretrizes Curriculares Nacionais para o Ensino de História e Cultura Afro-Brasileira e Africana (que estabelecem a educação das relações étnico-raciais como um dos eixos dos projetos político-pedagógicos das escolas) e a Lei $\mathrm{n}^{\mathrm{o}}$ 10.639/2003 (que institui a obrigatoriedade do ensino de história da África e da cultura afro-brasileira na educação básica).

Recentemente, em uma entrevista a respeito dos quatorze anos da Lei $\mathrm{n}^{0}$ 10.639/2003, Petronilha Beatriz Gonçalves Silva (2017) discorre sobre a questão das relações étnico-raciais na escola. Segundo ela, é possível dizer que a preocupação dos professores com a temática étnico-racial aumentou, mas que sua abordagem ainda depende da iniciativa individual dos docentes, não se caracterizando como uma política. Em outro estudo, a autora afirma que abordar pedagogicamente ou tomar como objeto de pesquisa os processos de ensinar e aprender em sociedades compostas por variados grupos étnicos, como o Brasil, requer dos professores e pesquisadores algumas ponderações (SILVA, 2007). Uma delas é não tomar como "naturais" os processos e tensionamentos étnico-raciais que se fazem presentes 
nas escolas e na sociedade. Outra é não examinar tais processos apenas pelo olhar econômico e social, mas considerar que a educação está diretamente implicada.

A pesquisa que sustentou a escrita deste artigo foi desenvolvida visando a problematizar tensionamentos étnico-raciais que se fazem presentes na escola e na cidade de Estrela. Estivemos atentas para examinar essas questões a partir das visões e concepções dos estudantes. Acompanhamos, nesse processo, investigações já realizadas sobre o tema, como as de Mello (2006), Weschenfelder (2012), Kern (2012) e Ramos (2009, 2014), as quais discutem a temática étnico-racial apoiando-se em referenciais teóricos similares aos utilizados neste estudo. Contudo, o foco delas não é, propriamente, a percepção dos alunos sobre as questões étnico-raciais, o que, em nosso trabalho, é o ponto central.

\section{0 contexto}

Nesta seção, propomo-nos a apresentar algumas reflexões sobre as relações étnico-raciais no município de Estrela. Dessa forma, seguimos as considerações de Veiga-Neto (2013), que, inspirado em Foucault, destaca a importância da dimensão histórica na compreensão de uma determinada realidade. Segundo ele, desnaturalizar as coisas, as identidades, as diferenças, enfim, desnaturalizar os fenômenos sociais, portanto, políticos, entendendo-os não como algo dado, mas construído historicamente pelas disputas de poder, é o primeiro e necessário passo para desconstruir aquilo que nos desagrada. Nas palavras do autor: "Saber como chegamos a ser o que somos é condição absolutamente necessária, ainda que insuficiente, para resistir, para desarmar, reverter, subverter o que somos e o que fazemos" (VEIGA-NETO, 2013, p. 7). Nesta busca de compreender "como chegamos a ser o que somos", recorremos a alguns elementos do passado, na tentativa de evidenciar a constituição das diferenças entre brancos e negros na cidade.

A discussão histórica brevemente apresentada não tem a pretensão de reescrever "A História" dos negros em Estrela, e, sim, rearranjar fragmentos de algumas histórias de modo que se coloquem em evidência os tensionamentos étnico-raciais que acompanharam este território desde o início de seu povoamento. Pesquisando informações acerca da história dos negros no município, percebemos o que alguns historiadores atuais relatam sobre o modo como eram tratados os negros na historiografia praticada no passado. Segundo eles, os historiadores brasileiros, no final do século XIX e início do século XX, omitiram informações sobre a resistência e a participação do negro na história do Rio Grande do Sul. Os relatos que existem 
sobre eles dizem respeito à separação entre negros e brancos ou às suas diferenças e não à sua contribuição à formação do município. Weschenfelder (2012, p. 72) explica esse mesmo processo quando se refere à historiografia de Santa Cruz do Sul e Venâncio Aires (cidades do Vale do Rio Pardo): "A consolidação de uma narrativa identitária que valorizou de sobremaneira os colonos alemães acabou por ignorar a presença de outros grupos étnicos”.

Assim, seguindo a historiografia tradicional, a história de Estrela, como grande parte dos municípios da Região do Vale do Taquari, RS, é marcada pelo processo de colonização de imigrantes alemães (KREUTZ, 1991; RAMBO, 1994). Porém, sabe-se que, além destes, outros grupos étnicos contribuíram para o desenvolvimento da região, entre eles, os negros, que, até o final do século XIX, viviam no local como escravos (SCHIERHOLT, 2002). Após o fim da escravidão, por não terem condições de adquirir bens, grande parte dos negros fixavam suas moradias em lugares desprezados pelos brancos e, na maioria das vezes, dependiam dos imigrantes alemães, que os contratavam como mão de obra para trabalhar nas suas lavouras. Os serviços pesados de carga e descarga nos portos, prestados pelos negros, fizeram com que muitos seguissem os barcos e se fixassem nas proximidades de Porto Alegre, reduzindo a população negra na cidade de Estrela.

Ao pesquisar as questões sociais que marcavam o município no final do século XIX e início do século XX, Schierholt (2002) afirma que as pessoas não se reconheciam como preconceituosas, inclusive negavam que fossem. No entanto, uma série de práticas sociais evidenciava que as ações não correspondiam a essa afirmativa, sobretudo no que se pode verificar nos casamentos, uma vez que havia uma "prevenção à miscigenação", ou seja, não há notícias de casamento que tenha ocorrido entre negro e branca ou entre negra e branco no período.

Ao descrever os costumes da "sociedade estrelense" no tocante às diferenças entre os espaços frequentados por brancos e negros, Schierholt (2002) afirma que as pessoas brancas tomavam precauções para evitar contato mais íntimo com pessoas negras. As sociedades dos brancos não admitiam negros como sócios, como o caso da Sociedade Ginástica de Estrela (Soges), fundada em 1906, e ainda em funcionamento. Não sendo sócios, os negros não podiam frequentar os bailes. Todavia, os negros, por sua vez, eram resistentes a permitir o casamento de seus(suas) filhos(as) com brancos(as). E, tal como os brancos, os negros tinham o seu próprio salão de festas e bailes.

Essas tensões foram evidenciadas na pesquisa realizada por Wanderer (2014), cujo objetivo foi analisar discursos sobre a escola produzidos por moradores da ci- 
dade de Estrela que estudaram no período da Campanha de Nacionalização (19371945). Nas entrevistas realizadas pela autora, evidenciam-se enunciações de que os alunos negros foram aceitos na escola para amenizar os efeitos da fiscalização do governo, que exigia aulas direcionadas à promoção dos elementos nacionais sem enaltecer outras culturas, no caso, a germânica. Naquele contexto, os negros também eram aceitos na escola para ensinar a língua portuguesa aos colegas, os quais, em suas famílias, só falavam em alemão. Mas, a todo instante, eram posicionados como "burros" ou "causadores de pequenos furtos". Apoiando-se em Hardt e Negri, Wanderer argumenta, então, que operava um mecanismo denominado de inclusão diferenciada, ou seja, todas as crianças (brancas e negras) frequentavam a escola, entretanto, as relações entre elas, bem como o trabalho pedagógico realizado, posicionavam de formas diferentes brancos e negros. No decorrer desse processo, surgiram tensões étnico-raciais, as quais persistiram e posicionaram os negros em uma situação de inferioridade perante os brancos.

Nas últimas décadas, Estrela tornou-se a segunda cidade em população do Vale do Taquari. O censo do Instituto Brasileiro de Geografia e Estatística (2010), informou uma população total de 30.619 pessoas residentes na cidade. Desse total, 27.339 declararam-se brancas; 962, pretas; 37, amarelas; 2.139 , pardas; e 142, indígenas. Observa-se que, dentre as pessoas negras e pardas, uma minoria ocupa a classe média e alta da população. Os moradores negros, em sua maioria, trabalham como empregados domésticos, na construção civil, em ateliês de calçados e indústrias, em que se exige mais força física e se recebe remuneração menor do que, por exemplo, nos setores do comércio e da prestação de serviços especializados (ANJOS, 2012).

Atualmente, percebem-se, entre os habitantes do município, tensionamentos advindos de questões étnico-raciais que se manifestam nas relações do trabalho, da educação e da convivência diária. Nos últimos anos, em especial, a cidade recebeu uma grande quantidade de imigrantes haitianos. Esse movimento migratório aconteceu entre 2012 e 2015, em função da relativa prosperidade econômica da região e, consequentemente, da maior demanda por mão de obra das empresas locais. A presença desses novos habitantes não é significada da mesma forma pelos cidadãos de Estrela. Por um lado, alguns ressaltam como positiva a possibilidade de novos empregados e consumidores; por outro, afloram as práticas discriminatórias em função dos marcadores de raça-etnia.

Os estudantes que frequentam a escola na qual realizamos a parte empírica desta investigação destacaram a existência de práticas discriminatórias contra 
os haitianos em Estrela. Nesse sentido, destacam-se os relatos de alguns desses alunos: “[...] eles [os haitianos] estão sofrendo racismo. Eles só estão aqui porque lá não tem como eles ficarem e conseguirem viver, né!?”; “Aqui na escola eles não sofrem, mas eu vejo as crianças vindo pra escola de tarde e tem gente que fica olhando. Eu acho que eles sofrem preconceito fora da escola".

O preconceito sentido fora da escola pode ser percebido, também, pelo que se pode interpretar, no bairro em que muitos haitianos residem. Como disse uma aluna, no caminho que as crianças fazem para a escola, "tem gente que fica olhando". Ela reconhece, nessa forma de olhar, uma forma de discriminação.

Relacionamos essa questão com o estudo de Soares e Andreola (2017), desenvolvido com o propósito de discutir significados atribuídos à presença haitiana no oeste catarinense, uma região marcada pela identidade branca, italiana e alemã. Os autores analisaram como a branquitude hegemônica produz efeitos nas relações entre moradores locais e imigrantes haitianos. Uma das dimensões destacadas no trabalho é que a branquitude, tomada como um lugar de poder, faz com que os negros sejam considerados indesejáveis na região cuja história supervaloriza a presença do imigrante de origem alemã ou italiana. Além disso, os estrangeiros haitianos são posicionados como uma espécie de ameaça à branquitude, que se faz presente nas relações sociais e afetivas. Assim, os brancos produzem um desejo de distanciamento da população negra, para, de certa forma, proteger seus privilégios.

Nessa direção, conforme Santos (2018), ao mencionarmos as questões sobre racismo, estamos nos referindo a um processo dicotômico: de um lado, ficariam os grupos racializados na sociedade (negros, ciganos, indígenas); do outro, aqueles que se beneficiam por essa racialização, como os brancos. Dessa forma, as relações raciais devem ser examinadas não apenas pelo viés dos grupos afetados, mas também pela perspectiva do grupo branco. Para Santos (2018, p. 553), ao desconsiderarmos "[...] a análise do outro polo da discriminação, acabamos por confirmar o falso discurso de que o racismo é um problema dos grupos afetados, portanto somente eles devem ser estudados; somente eles permanecem o outro, o objeto a ser dissecado".

Esses tensionamentos também se fazem presentes em Estrela, como apresentado brevemente nesta seção. A fim de ampliar essa discussão, realizamos uma investigação com o propósito de analisar as enunciações de alunos dos anos finais do ensino fundamental sobre as relações étnico-raciais presentes na escola e na cidade. 


\section{A produção do material empírico}

A pesquisa que gerou a escrita deste artigo se caracteriza como uma investigação de inspiração etnográfica, conduzida pela primeira autora do artigo. A emergência da etnografia nas escolas é um fenômeno recente. Segundo Green, Dixon e Zaharlick (2005), seu reconhecimento enquanto abordagem de pesquisa para os problemas e as investigações pertinentes à educação iniciou na metade do século XX. As autoras afirmam que a tarefa do etnógrafo, dentro da escola, é apontar "[...] as maneiras pelas quais os membros do grupo estudado percebem sua realidade e seu mundo, e como, por intermédio de suas ações (e interações) constituem seus valores, crenças, ideias e sistemas simbólicos significativos" (GREEN; DIXON; ZAHARLICK, 2005, p. 13).

Todavia, elas fazem um alerta sobre os cuidados que se deve ter no momento da investigação ao assumir essa abordagem de pesquisa, entre os quais estão não entrar no ambiente escolar com uma lista de itens predefinida ou com questões e hipóteses predeterminadas e não projetar um esquema de observação que defina a priori todos os comportamentos ou eventos que serão registrados. As autoras reforçam que, "[...] se o observador não se basear em teorias da cultura para direcionar as escolhas do que é relevante observar e registrar [...] [e] abranger sua interpretação pessoal a respeito da atividade observada [...]" (GREEN; DIXON; ZAHARLICK, 2005, p. 13), o pesquisador não estará se engajando em uma abordagem etnográfica como percebida do ponto de vista antropológico.

Guber (2001) questiona a validade de escrever sobre o trabalho de campo etnográfico no início do século XXI, considerando o fato de a etnografia ser uma "metodologia artesanal", diante de um mundo em que predomina a informática, as pesquisas de opinião e a internet. A autora afirma que a importância da etnografia se faz exatamente para evitar a relativização das perplexidades deste mundo globalizado, e completa afirmando que a complexidade presente nas relações humanas é o que move cada vez mais profissionais, entre os quais os pesquisadores/educadores.

No trabalho de campo que empreendemos, foram utilizadas técnicas como a escrita em um diário de campo, observações na escola e realização de atividades pedagógicas em uma turma de $8^{\circ}$ ano do ensino fundamental, composta por 21 alunos. A escolha dessa turma não foi aleatória; segundo relato da direção, ela era, dentre as demais turmas, a que tinha o maior número de alunos negros. Cabe ressaltar que os responsáveis por todos os estudantes assinaram o termo de consentimento livre e esclarecido após serem informados sobre os objetivos da pesquisa, de acordo com as normas de ética nas pesquisas em ciências humanas e sociais. 
Ao todo, foram oito meses frequentando a escola e seus espaços, entre outubro de 2015 e dezembro de 2016. Como esse tempo não foi contínuo, podemos afirmar que o trabalho de campo se dividiu em duas fases, complementares entre si: um período de observações de aulas e de diferentes momentos do cotidiano escolar, como recreio e sala dos professores, e a fase da realização de atividades pedagógicas sobre as questões étnico-raciais.

Desde o início, o diário de campo esteve presente, cujo conteúdo compreende descrições e relatos de conversas informais com professores e funcionários da escola. Ao mesmo tempo, observações foram realizadas em sala de aula para que pudéssemos conhecer melhor os alunos com os quais desenvolveríamos as atividades pedagógicas. Nosso objetivo, com essas atividades, foi o de visibilizar histórias e relatos advindos dos próprios estudantes, a partir de suas experiências com as relações étnico-raciais na escola e na sociedade.

A primeira dessas atividades consistiu na análise de imagens projetadas por um data-show disponível na escola. Foram apresentadas as imagens apresentadas na Figura 1, contendo carro, celular, casa, roupas, sala de aula e placa de aprovação em vestibular.

Figura 1 - Imagens da atividade
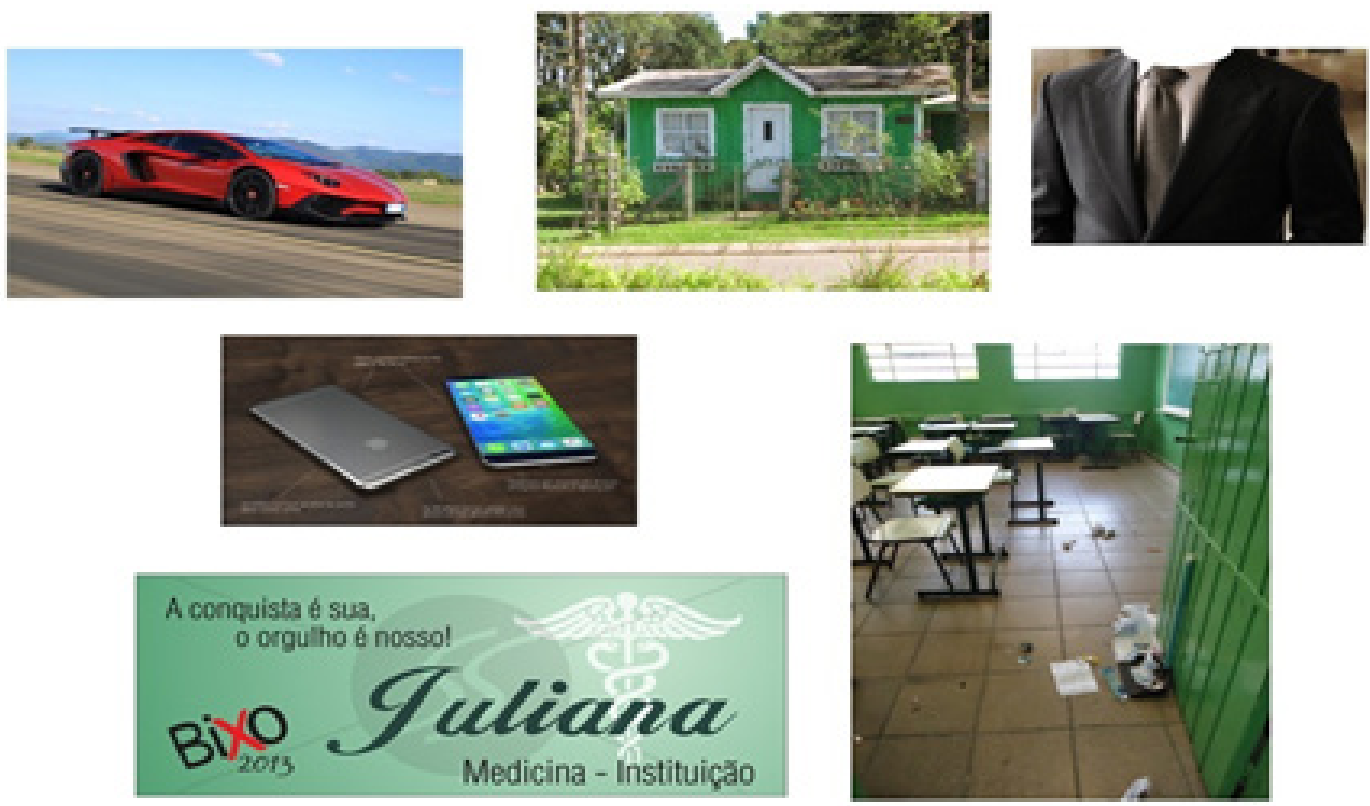

Fonte: disponível em: <http://casa.abril.com.br/tudo-sobre/casas/>. Acesso em: 27 fev. 2016. 
Os alunos foram questionados sobre o que as imagens representavam, quem seria proprietário do que estava sendo mostrado, o que essas pessoas faziam, qual sua descrição física, etc. É importante destacar que a escolha das imagens buscou ir ao encontro do universo jovem e escolar para envolver os alunos. $\mathrm{O}$ objetivo principal era fazê-los narrar seu modo de ver e viver o mundo, dando ênfase às questões étnico-raciais.

Processo semelhante foi usado por Melo (2016) na produção empírica da sua dissertação, intitulada Representações de professores e de alunos sobre a Provinha Brasil. Como seu objetivo era analisar o que representava a Provinha Brasil na perspectiva dos alunos, a pesquisadora criou uma ferramenta metodológica que denominou de "aula-conversa". Essa ferramenta consistia em um "[...] momento que contempla toda a turma, feito na própria sala de aula e com auxílio da professora titular da turma, em que são solicitadas atividades e realizados diálogos para interlocução entre alunos e pesquisadora" (MELO, 2016, p. 50). Essa estratégia metodológica proporcionou um clima de confiança e produtividade para o seu objeto de pesquisa, crianças entre 8 e 9 anos. Em nosso estudo, o importante era tornar o clima mais informal, para favorecer a participação dos adolescentes.

Os alunos foram muito participativos com a descrição das imagens e contribuíram com diferentes comentários sobre as figuras, que foram projetadas, uma a uma, na parede. Quando apareceu o carro, por exemplo, logo um menino disse: "É dos Velozes e Furiosos". Outro retrucou: "Não é não, este aí é carro de gente rica dar um rolé". Um estudante respondeu: "Sora, posso trabalhar minha vida toda que não vou ter um carro assim". Ainda em relação à imagem do carro, a discussão foi atravessada pela questão de gênero, pois uma menina disse: "Acho que este carro é de uma mulher". Outro aluno, nesse momento, retrucou: "Mulher não sabe dirigir este carrão!". Então, mais meninas intervieram na discussão e questionaram o colega sobre o motivo pelo qual as mulheres não poderiam dirigir aquele carro.

A imagem da casa também favoreceu uma intensa discussão. Os alunos concordaram que a moradia era de uma senhora, pois havia um canteiro com flores, o que, para eles, corroborava essa interpretação. Porém, quanto à classe social da proprietária da casa, não houve consenso: "A casa é de alguém de classe média, pois ter uma casa própria hoje em dia é difícil"; "Acho que não, pois a casa é bem simples, de madeira"; "Sora, a dona não tá nem aí para a aparência da casa, para ela o importante é ter tecnologia, olha a antena da Sky".

A segunda atividade trabalhada foi referente à discussão das imagens apresentadas na Figura 2. 
Figura 2 - Rostos

\section{Com quem você se identifica?}

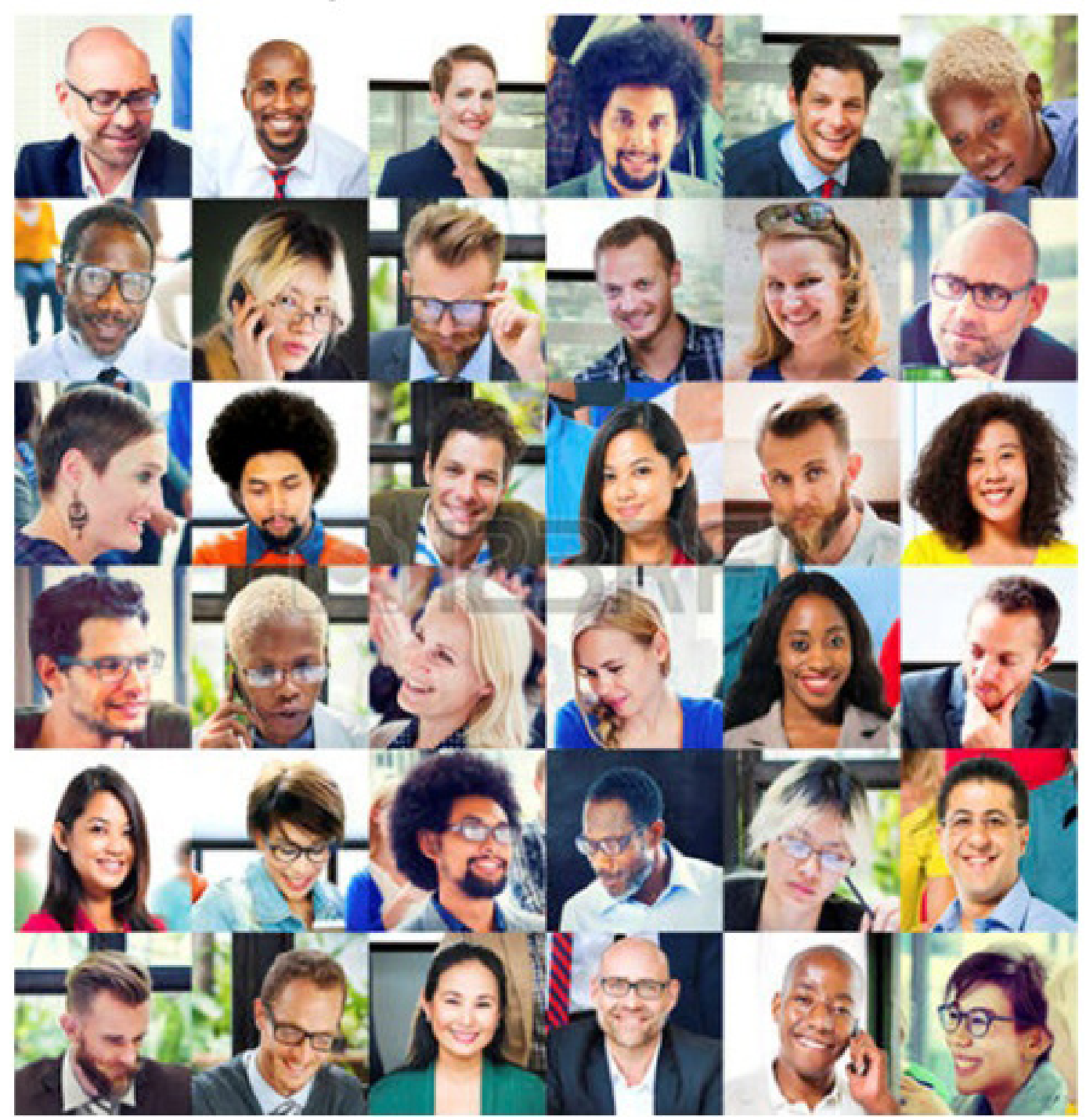

Fonte: disponível em: <http://www.blogdopilako.com.br/>. Acesso em: 27 fev. 2016.

O objetivo da segunda atividade foi averiguar quais são as marcas étnico-raciais com que os alunos se identificam. Para isso, cada aluno foi convidado a se aproximar das imagens que estavam sendo projetadas, indicar com qual daquelas 
pessoas mais se identificava e explicara o porquê da escolha. Durante a realização dessa atividade, também houve boa participação dos jovens. Apareceram comentários como este: "Não me identifico com nenhum, pois sou bonito e aí só tem gente feia". Mas, quando um menino escolheu a imagem de um rapaz de pele branca, imediatamente os colegas fizeram críticas à sua escolha: "Esse aí é muito branco, tu é moreno, cara!"; "Nada a ver, olha a tua cor".

Outra atividade explorou como as relações étnico-raciais são "negociadas" na arte e na mídia. Para isso, foram projetadas imagens de personagens famosos (Monalisa, Super-Homem, Mulher-Maravilha, Elsa, Harry Potter e Menino Maluquinho), com o diferencial de que eles estavam representados por atores e atrizes negros. As imagens integravam uma mostra, de 2016, realizada no Rio de Janeiro, intitulada Identidade. Foi debatida a frequência com que personagens negros aparecem na arte e na mídia. Imediatamente, os estudantes perceberam que todos os personagens estavam representados por pessoas negras e falaram: "Eles estão afrodescendentes!". Uma menina foi além e disse: "Sora, normalmente é o contrário, olha na TV, os negros são pobres ou traficantes". Na sequência, alguns disseram: "Eles [os brancos] são mais aceitos". Outra menina ainda disse: "Sora, a Monalisa está bem mais bonita morena!".

A complexidade dessa situação nos remete ao texto "Das (im)possibilidades de se ver como anjo...", de Meyer (2011), no qual a autora problematiza o fato de uma menina negra de 3 anos não querer mais ir para a escola, pois, segundo relatou à sua mãe, ela tinha descoberto que, na escola, não podia ser anjo. Meyer (2011, p. 39) lembra o peso das imagens e da linguagem visual na etapa de ensino daquela menina e faz um questionamento: "Quantos/as de nós [professores de educação infantil e séries iniciais] já vimos ou já trabalhamos com imagens em que os anjos retratados não fossem meninos (ou seres assexuados) de pele muito branca, com cabelos louros e encaracolados e olhos azuis?". Relacionando essa questão com o universo dos alunos que participaram desta pesquisa, podemos dizer que, muitas vezes, eles também são impossibilitados de se identificar com as imagens projetadas pela mídia, como os relatos citados indicam.

A última atividade realizada envolveu uma análise do vídeo Vista minha pele. O curta-metragem mostra a história de uma menina branca que vive entre pessoas negras e se sente discriminada. Na história, os negros são a classe dominante, e os brancos foram escravizados. Maria, a menina branca e pobre, estuda em um colégio particular graças à bolsa de estudos que tem pelo fato de sua mãe ser faxineira da escola. A maioria de seus colegas a hostilizam, pela cor de sua pele e por sua condi- 
ção social. A menina quer ser Miss Festa Junina da escola, no entanto, isso requer um esforço enorme, que vai desde a superação da supremacia racial negra (a mídia só apresenta modelos negros como sinônimo de beleza), passando pela resistência de seus pais, até a aversão dos colegas e a dificuldade em vender o número requerido de ingressos para seus conhecidos, em sua maioria muito pobres. Maria conta apenas com a ajuda de sua amiga Luana, cujo pai é diplomata e, por ter morado em países pobres e convivido com pessoas brancas, apresenta uma atitude acolhedora para com a protagonista. Na sequência do vídeo, as duas se envolvem em uma série de situações para alcançar seus objetivos.

Ao discutir o vídeo com os alunos, algumas falas chamaram a atenção: "A realidade é ao contrário"; e "[...] no filme dizia que cabelo escorrido tem solução, geralmente se diz que cabelo cacheado tem solução". Esses comentários demonstram que os alunos percebem a discriminação existente em relação aos negros, seja pelo tipo de cabelo, seja pela cor da pele. O filme também fez alguns alunos refletirem sobre questões que ainda não haviam aparecido nas discussões, como: "Eu nunca tive um professor negro"; e "[...] nunca se fala destas coisas [discriminação racial] aqui na escola, só se o cara está muito perseguido, daí vem alguém falar na sala, mas não lembro de ter vindo alguém".

Com a realização dessas atividades, foi possível produzir o material de pesquisa escrutinado neste estudo. A estratégia analítica utilizada para operar sobre esse material é a análise do discurso na perspectiva de Michel Foucault. Na entrevista sobre o lançamento da obra A arqueologia do saber, o filósofo buscou explicar quais são os objetivos da análise do discurso, deixando claro que não se trata puramente de descrever um discurso ou buscar fatos escondidos esperando para ser escavado. O autor explica: “Tento, ao contrário, definir relações que estão na superfície dos discursos; tento tornar visível o que só é invisível por estar muito na superfície das coisas." (FOUCAULT, 2002 apud FISCHER, 2012, p. 25).

Inspirando-se em Foucault, Fischer (2012) explica que a análise do discurso trata basicamente da análise dos enunciados. Sobre descrever enunciados, ela afirma: "[...] significa apreender as coisas ditas como acontecimentos, como algo que irrompe num tempo e num espaço muito específicos, ou seja, no interior de uma formação discursiva” (FISCHER, 2012, p. 101). E completa: “[...] esse feixe complexo de relações [é] que 'faz' com que algumas coisas possam ser ditas (e recebidas como verdadeiras) num certo momento e num lugar" (FISCHER, 2012, p. 101).

Na obra A ordem do discurso, Foucault (2009) reflete sobre os procedimentos que estabelecem, dentre as coisas que podem ser ditas, aquilo que é verdadeiro e 
aquilo que é falso. O filósofo explica que um discurso, em si mesmo, não é verdadeiro nem falso. $\mathrm{O}$ que acontece é que os discursos inventam verdades a partir de seu vínculo com as relações de poder. Os discursos, na concepção foucaultiana, são perpassados por lutas políticas.

Entendemos, com base em Foucault e nas reflexões de Fischer (2012) e Veiga-Neto (2014), que tratar dos discursos e das relações de poder nas práticas cotidianas, dentro e fora da escola, é um modo de verificar como a história interpela os sujeitos, bem como se constitui em um modo de fazer a história do nosso presente, lançando um olhar crítico a todas as formas de sujeição do homem, especificamente, nesta pesquisa, dos negros. Assim, seguindo a inspiração foucaultiana, analisamos as enunciações produzidas pelos alunos que integraram esta pesquisa não no sentido de encontrar o que está oculto, mas para dar ênfase a certos enunciados que passam a ser aceitos, transmitidos e deixam de ser questionados. $\mathrm{O}$ resultado dessa operação será apresentado na próxima seção.

\section{Relações étnico-raciais e seus tensionamentos}

Analisando as enunciações dos alunos ao longo da experiência pedagógica realizada e as observações registradas no diário de campo, pudemos construir uma analítica que evidencia de que forma operam, na escola e na sociedade, os tensionamentos étnico-raciais. Uma das facetas dessa analítica se refere à existência de práticas discriminatórias na cidade onde vivem os estudantes, em especial, em relação aos negros. Durante as atividades pedagógicas, essa questão pôde ser percebida em uma discussão entre os alunos, quando foi projetada a imagem de um carro esportivo de luxo. Um deles falou: "O carro é de um homem rico, um advogado, usa terno. Se é rico e advogado, é branco". Outro estudante exclamou: "Pode ser preto, também". Uma das alunas, na sequência, disse: "Pode ser uma mulher". E, o primeiro aluno a se manifestar, completou: "Você vê homem preto com um carro assim andando por aí?".

Como se pode ver, a questão gerou polêmica na turma, tanto no que diz respeito à raça e à etnia do condutor do veículo, quanto em relação ao seu gênero. Nesse sentido, vemos que há um atravessamento de duas marcas discursivas fundamentais: a disparidade social entre brancos e negros, evidenciada na fala: "Você vê homem preto com um carro assim andando por aí?"; e a questão de gênero, segundo a qual são reservados para homens e mulheres certos papéis na sociedade. Porém, essa ideia aparece rasurada pela fala da menina: "E pode ser uma mulher". 
Essa alusão à inferioridade dos negros na sociedade foi recorrente nos comentários dos alunos ao longo das aulas observadas e das atividades desenvolvidas em sala de aula. Algumas de suas enunciações refletem isso, como no comentário de uma aluna negra: "Não tem motivo especial para ter racismo aqui em Estrela, mas a gente consegue ver pela reação das pessoas quando a gente passa. Muitas vezes, as pessoas te olham torto, ou elas começam a cochichar, ou alguma coisa assim". Outro estudante negro também expressou: "Eu estava junto com meu primo, que é negro, dentro do mercado. A dona do mercado começou a nos seguir, achando que nós ia roubar alguma coisa. Nós nos indignemos e falemos umas verdades pra ela".

Essa última enunciação evidencia uma das principais formas de discriminação racial no Brasil, isto é, a relação entre a negritude e a marginalidade. Conforme a fala do aluno, ele e seu primo foram considerados potenciais ladrões apenas pela sua aparência, no que ele destaca o fato de o "primo" ser "negro". De acordo com Ramos, Santana e Santana (2011, p. 13), o preconceito "[...] pode ser definido, também, como uma indisposição, um julgamento prévio, negativo, que se faz de pessoas estigmatizadas por estereótipos". Nesse sentido, parece que o próprio aluno se mostra capturado por essa lógica, visto que nega sua própria negritude, ao mesmo tempo que explicita um ato discriminatório, relaciona-o à cor da pele do primo, e não à sua própria condição racial.

Todavia, talvez mais importante do que essa possível interpretação, tem-se o fato de esse aluno associar-se ao primo para reagir àquilo que ambos consideraram demasiadamente ofensivo e, diante da mulher que os seguia, indignarem-se e falarem "umas verdades pra ela". Nesse ponto, fica clara sua resistência ao preconceito racial, ao mesmo tempo em que se percebem os tensionamentos provenientes das questões étnico-raciais na cidade onde residem.

As falas dos alunos mostram que o racismo não está associado apenas a uma prática específica, como seguir os negros no interior de um mercado. É percebido também nas reações das pessoas. Como afirmou um dos discentes: "As pessoas te olham torto, ou elas começam a cochichar". Fica evidente, portanto, uma separação entre aqueles que apenas "passam na rua" e aqueles que, além de passar, veem-se no direito de cochichar sobre os outros. Nesse sentido, é importante notar o quanto o "olhar torto" e outras expressões ou gestos podem deixar marcas na identidade dos sujeitos negros. Conforme Ramos, Santana e Santana (2011, p. 17): "É pelo olhar do outro que me constituo como sujeito. É a qualidade desse olhar que contribui para o grau de autoestima da criança [...]", no caso, os adolescentes negros da escola pesquisada. 
Nesse sentido, é interessante observar que, mesmo se referindo ao racismo na sociedade, quando os alunos falavam sobre a escola, afirmavam que não há práticas discriminatórias na instituição. Muitos expressaram que "racismo, aqui na escola, não tem. Acho que todo mundo é aceito". Outra aluna também se referiu a isso quando disse: "Que eu saiba, não existe racismo na nossa escola, mas, na nossa cidade, existe. Já vi várias pessoas sofrendo racismo ou algo parecido". Assim, poucos manifestaram que práticas racistas se fazem presentes na escola: "Racismo existe em todo lugar, tanto na fila do supermercado, no banco, na rua, na escola, e os exemplos é só acompanhar as notícias".

$\mathrm{Na}$ mesma direção, disse uma estudante: "Na minha escola, acho que é pouco racismo, é só quando o preto tem cabelo feio, daí acontece por isso". Nota-se que, nesse contexto, o racismo não diz respeito à cor da pele, mas a algo que os estudantes relacionam à "estética" do cabelo. Uma situação semelhante foi encontrada por Ramos, Santana e Santana (2011), que examinaram as formas pelas quais adolescentes negras lidavam com seus cabelos crespos. Grande parte delas não gostavam de seu cabelo, e o motivo seria porque os colegas falavam mal, dizendo ser "feio". O cabelo, nesse sentido, parece reforçar marcas de negritude, que afastam aqueles que têm o cabelo "feio" daqueles cujo cabelo não corresponde a essas marcas.

Podemos, por um lado, explicar a ausência de racismo na escola pelo modo como os alunos se descrevem. Ao não se identificarem como negros, não se vê a possibilidade, em um primeiro momento, de práticas de discriminação racial. Nisso se encontra outra faceta da análise empreendida nesta pesquisa: os alunos não se identificam com sua negritude, autodenominando-se de "morenos" ou "meio morenos".

Nas atividades, uma das propostas era que os estudantes indicassem um dos rostos projetados em slides com o qual se identificavam. Como já mencionado, um aluno negro escolheu a imagem de um rapaz de pele branca, e, imediatamente, os colegas fizeram críticas à sua escolha, dizendo: "Esse aí é muito branco, tu é moreno, cara!"; "Nada a ver, olha tua cor". O fato evidencia que o aluno em questão não se identifica com a cor da pele que os outros veem que ele tem, isto é, nesse caso, a não naturalidade da cor fica demonstrada. Também ocorreu um diálogo que merece destaque. Os discentes deveriam se narrar, momento em que um menino disse que era moreno, relatando: "Não sei por que me chamam de preto. Eu não sou preto, sou moreno. Preto é quando não dá para enxergar". Ao ser questionado se tem alguém preto na escola, respondeu prontamente: "Tem os haitianos". 
Percebemos, novamente, nas enunciações supracitadas, que o pertencimento étnico-racial se constitui em um processo envolto em tensões que, frequentemente, geram negação ou rejeição ao sentimento de pertença a um determinado grupo. Nesse caso, mais uma vez, emerge a ideia de que os alunos da escola não são negros, e a justificativa está na comparação que estes realizam com os haitianos, cuja cor da pele identificam como sendo "mais escura".

Nota-se um traço bastante característico da questão racial no Brasil, onde se criaram diversas denominações para, supostamente, referir-se às muitas configurações raciais provenientes do complexo processo de miscigenação que produziu o nosso povo. Mozart Linhares da Silva (2007), no entanto, chama a atenção para o fato de que há, na criação dessas novas denominações, um aspecto igualmente cultural, não relacionado apenas à cor da pele, mas contendo uma acepção que diz respeito às representações sociais, e que, em certo sentido, indicam as tensões étnico-raciais presentes no país. Segundo Mozart Linhares da Silva (2007, p. 72), merecem justamente atenção as categorias "moreno(a)", "claro(a)" ou "escuro(a)", porque o "[...] moreno não apenas amolece a rigidez das polarizações, mas também implica um processo de deslizamento do 'preto' para o 'branco". Nesse sentido, percebe-se, nessa visão, a ideia de que ser negro é algo negativo, enquanto ser "moreno" reduz essa negatividade.

Discutindo sobre as questões referentes a raça e etnia, Silva (2014) afirma que a identidade não deve ser naturalizada, cristalizada, nem essencializada. Destaca que a identidade é uma construção, refere-se a um modo de ser no mundo e estar com os outros. O autor ressalta que é preciso evitar o essencialismo cultural, por mais sutil que se apresente: "[...] o essencialismo cultural concebe a identidade simplesmente como a expressão de alguma propriedade intrínseca dos diferentes grupos étnicos e raciais. Nessa concepção a identidade, embora cultural, é vista como fixa e absoluta" (SILVA, 2014, p. 104). Seguindo as discussões do autor, entendemos que as relações étnico-raciais possuem vários atravessamentos engendrados por relações de poder que não podem, nem devem, ser reduzidos a um olhar "naturalizado" sobre os modos de ser negro. Ou seja, a construção da identidade negra passa por muitas questões como sua história de vida, sua relação com a escola e com a sociedade.

Nesse sentido, buscamos apoio em Larrosa (2011, p. 147), quando afirma: “[...] o sentido de quem somos está construído narrativamente [...]”. Assim, a constitui- 
ção do sujeito é um processo efetuado pelas várias narrativas feitas pelo próprio "eu" e pelos "outros", ao longo de suas trajetórias. As histórias de vida são tomadas como produtoras de identidades, havendo uma relação muito estreita entre aquilo que somos e as histórias (narrativas) que ouvimos, que lemos e que contamos. Como se pode perceber nas enunciações dos alunos acerca dos haitianos, eles consideram que estes são negros, mas não associam essa denominação à sua própria condição racial, porque, ao se compararem, consideram-se "menos escuros", portanto, não se veem como negros.

A discussão realizada por Hardt e Negri (2004) sobre o conceito de racismo imperial nos ajuda a compreender melhor essa não identificação de muitos alunos como negros. Nas palavras dos autores, "[...] o racismo imperial, ou racismo diferenciado, integra outros à sua ordem e então orquestra essas diferenças num sistema de controle" (HARDT; NEGRI, 2004, p. 216). Eles utilizam o termo racismo imperial para argumentar que, ao contrário do que imaginamos, o racismo não diminuiu, visto que, apesar de práticas como o apartheid e a escravidão terem deixado de existir, o racismo passou a adotar novas estratégias, mais sutis, infiltrando-se disfarçadamente em diversas práticas sociais. "O racismo não retrocedeu, e que na realidade progrediu no mundo contemporâneo, tanto em extensão como em intensidade. Só parece ter declinado porque suas formas e estratégias mudaram" (HARDT; NEGRI, 2004, p. 210).

$\mathrm{Na}$ configuração do racismo imperial, não estamos diante de uma oposição binária marcada pela cor da pele, e, sim, por questões que transcendem essa diferenciação. Para Hardt e Negri (2004, p. 213), “[...] as diferenças biológicas foram substituídas por significadores culturais [...]. As diferenças são, portanto, não fixas e imutáveis, mas efeitos contingentes da história social [...]”. Isso significa que a "supremacia branca" não se configura apenas como a supremacia das pessoas de pele branca, mas daquelas que, além disso, pensam e se comportam de "modo superior", bem como têm os valores considerados "superiores".

Os autores explicam que, na lógica do Império, a exclusão racial emerge como resultado da inclusão diferenciada. Nesse sentido, as práticas racistas não funcionam por exclusão, pois "[...] nenhuma identidade é designada como o Outro, ninguém é excluído do domínio, não existe lado de fora [...]" (HARDT; NEGRI, 2004, p. 215). Assim, o racismo imperial atua por inclusão e subordinação: "A supremacia branca funciona, de preferência, primeiro atraindo a alteridade e depois subordinando as diferenças de acordo com graus de desvio da brancura" (HARDT; 
NEGRI, 2004, p. 215), o que se confirma quando os alunos se autodenominam como "morenos" ou, em um grau menor de desvio da brancura, "meio morenos".

\section{Considerações finais}

Ao encerrarmos a escrita deste artigo, remetemo-nos a uma citação de Bauman (2005, p. 47): “Sempre há um número demasiado deles. 'Eles' são os sujeitos dos quais devia haver menos - ou, melhor ainda, nenhum. E nunca há um número suficiente de nós. 'Nós' são as pessoas das quais devia haver mais”. O sociólogo usa a expressão "nós" para se referir às pessoas que estão plenamente inseridas no sistema econômico vigente, alcançaram sucesso profissional e boas condições financeiras e, desse lugar na sociedade, olham para quem se encontra à margem desse sistema econômico. Contudo, lendo atentamente suas palavras, podemos atribuir outros sentidos para "eles" e "nós". "Eles" poderiam ser, por exemplo, na Europa, os refugiados de guerra, enquanto, no Brasil, poderiam ser os haitianos ou senegaleses que migram em busca de uma vida melhor. Mas também podemos fazer outras aproximações e identificar "eles" nas ruas, nas praças, nas periferias, nas escolas, enfim, em muitos lugares.

Relacionando a discussão de Bauman ao contexto em que realizamos esta pesquisa, na cidade de Estrela, percebemos que "eles" são, entre outros, os negros que habitam a cidade. Esse aspecto se evidenciou ao longo do período de permanência na escola, quando os alunos foram incitados a discutir e conversar sobre os tensionamentos étnico-raciais, e na analítica construída a partir do referencial teórico utilizado. O que os estudantes disseram sobre si mesmos e sobre aquilo que percebem na escola e na cidade - ou seja, que em Estrela há práticas racistas, mas não na escola - são enunciações capturadas pelo discurso segundo o qual o Brasil é um país onde impera uma democracia racial.

Além disso, os alunos mostraram um não reconhecimento de sua negritude, preferindo denominar-se como "morenos". Segundo eles, negros são apenas os haitianos, em função do tom mais escuro de sua pele. Esse aspecto corroborou as afirmações de Mozart Linhares da Silva (2007), quando o autor menciona que, no Brasil, há um "amolecimento" da rigidez das polarizações, o qual se materializa em novas denominações, como é o caso de "moreno", que apareceu na fala dos discentes.

De acordo com o desenvolvido no artigo, gostaríamos de destacar algumas reflexões sobre o lugar da escola em relação às discussões étnico-raciais. Seguin- 
do Gomes (2003), é tarefa do educador compreender o conjunto de representações sobre o negro existente na sociedade e na escola, produzindo práticas pedagógicas de combate às discriminações. Podemos dizer que, de alguma forma, o trabalho pedagógico que gerou o material de pesquisa escrutinado possibilitou que os alunos refletissem sobre si mesmos e sobre questões mais amplas, relativas à sociedade em que vivem. A escola pós-moderna tem se configurado como um espaço de problematização das grandes "verdades", o que leva à impossibilidade de se pensar a educação de modo desarticulado das questões de diferença, cultura, raça, gênero e tantas outras. Portanto, acreditamos que esta investigação contribuiu abrindo espaço para narrativas dos alunos acerca das questões étnico-raciais.

Por fim, cabe destacar que, enquanto pesquisadoras, procuramos exercer um constante e permanente questionamento sobre nossas ideias e concepções a respeito do tema investigado. Esse exercício é chamado por Veiga-Neto (2013) de hipercrítica. Segundo o autor, esta crítica radical é "[...] um tipo de desconstrucionismo que faz da crítica uma prática permanente e intransigente até consigo mesma, de modo a estranhar e desfamiliarizar o que parecia tranquilo e acordado entre todos" (VEIGA-NETO, 2013, p. 15). A prática da hipercrítica é um exercício delicado e complexo, uma vez que exige do pesquisador um olhar vigilante para que sua visão de mundo não se imponha a seu objeto de pesquisa, e que suas verdades não interfiram em sua análise. Da mesma forma que não podemos nos libertar de nosso próprio modo de ver o mundo, precisamos dar voz ao modo como os outros o veem. Foi o que buscamos realizar, tanto na condução do trabalho empírico quanto na escrita deste artigo.

\section{Referências}

ANJOS, Gilson Luiz. (Re)Conhecimento e negritude: uma questão da educação? 2012. 90 f. Dissertação (Mestrado em Educação) - Programa de Pós-Graduação em Educação, Universidade Federal do Rio Grande do Sul, Porto Alegre, 2012.

BAUMAN, Zygmunt. Vidas desperdiçadas. Rio de Janeiro: Zahar, 2005.

FISCHER, Rosa Maria Bueno. Trabalhar com Foucault: arqueologia de uma paixão. Belo Horizonte: Autêntica, 2012.

FOUCAULT, Michel. A ordem do discurso: aula inaugural no Collège de France. São Paulo: Loyola, 2009.

GOMES, Nilma Lino. Cultura negra e educação. Revista Brasileira de Educação, Rio de Janeiro, n. 23, p. 75-85, 2003. 
GREEN, Judith L.; DIXON, Carol N.; ZAHARLICK, Amy. A etnografia como uma lógica de investigação. Educação em Revista, Belo Horizonte, n. 42, p. 13-79, dez. 2005.

GUBER, Rosana. La etnografía: método, campo y reflexividad. Buenos Aires: Norma, 2001.

HARDT, Michael; NEGRI, Antonio. Império. 6. ed. Rio de Janeiro: Record, 2004.

INSTITUTO BRASILEIRO DE GEOGRAFIA E ESTATÍSTICA. Censo 2010. 2010. Disponível em: <https://censo2010.ibge.gov.br/\#>. Acesso em: 13 maio 2017.

INSTITUTO DE PESQUISA ECONÔMICA APLICADA. O longo combate às desigualdades raciais. 2017. Disponível em: <http://www.ipea.gov.br/igualdaderacial/index.php?option=com_ content\&view=article\&id=711>. Acesso em: 13 maio 2017.

KERN, Gustavo da Silva. Ações afirmativas e educação: um estudo genealógico sobre as relações raciais no Brasil. 2012. 182 f. Dissertação (Mestrado em Educação) - Programa de Pós-Graduação em Educação, Universidade Federal do Rio Grande do Sul, Porto Alegre, 2012.

KREUTZ, Lúcio. O professor paroquial: magistério e imigração alemã. Porto Alegre: Editora da Ufrgs, 1991.

LARROSA, Jorge. Tecnologias do eu e educação. In: SILVA, Tomaz Tadeu da (Org.). O sujeito da educação: estudos foucaultianos. 8. ed. Petrópolis: Vozes, 2011. p. 35-86.

MEINERZ, Carla Beatriz; PEREIRA, Priscila Nunes. Educação das relações étnico-raciais e superação da branquitude. Identidade, São Leopoldo, v. 23, n. 1, p. 161-180, jan./jul. 2018.

MELLO, Rosália Maria. É a cor da pele que faz a pessoa ser discriminada: narrativas sobre o negro e a discriminação racial produzidas em uma experiência pedagógica de educação matemática. 2006. 112 f. Dissertação (Mestrado em Educação) - Programa de Pós-Graduação em Educação, Universidade do Vale do Rio dos Sinos, São Leopoldo, 2006.

MELO, Camila Alves. Representações de professores e de alunos sobre a Provinha Brasil. 2016. 139 f. Dissertação (Mestrado em Educação) - Programa de Pós-Graduação em Educação, Universidade Federal do Rio Grande do Sul, Porto Alegre, 2016.

MEYER, Dagmar Estermann. Das (im)possibilidades de se ver como anjo... In: GOMES, Nilma Lino; SILVA, Petronilha Beatriz Gonçalves (Org.). Experiências étnico-culturais para a formação de professores. Belo Horizonte: Autêntica, 2011. p. 51-69.

MUNANGA, Kabengele. Rediscutindo a mestiçagem no Brasil: identidade nacional versus identidade negra. Petrópolis: Vozes, 1999.

RAMBO, Arthur Blásio. A escola comunitária teuto-brasileira católica. São Leopoldo: Unisinos, 1994.

RAMOS, Aline Oliveira; SANTANA, Marise de; SANTANA, José Valdir Jesus de. Relações étnico-raciais no ambiente escolar: reflexões a partir de uma escola pública no município de Itapetinga/BA. Educação, Gestão e Sociedade, São Paulo, ano 1, n. 2, p. 1-32, jun. 2011.

RAMOS, Tanise Muller. Tecendo tramas, traçando gentes: narrativas constituindo identidades em uma escola municipal de Porto Alegre/RS no ensino da história e cultura africana e afro-brasileira. 2009. 239 f. Dissertação (Mestrado em Educação) - Programa de Pós-Graduação em Educação, Universidade Federal do Rio Grande do Sul, Porto Alegre, 2009. 
"Nossos antepassados eram africanos, então somos negros também!": as intervenções pedagógicas na promoção das relações étnico-raciais e na constituição das identidades discentes. 2014. 144 f. Tese (Doutorado em Educação) - Programa de Pós-Graduação em Educação, Universidade Federal do Rio Grande do Sul, Porto Alegre, 2014.

SANTOS, Wellington Oliveira. Discursos sobre raça, racismo e educação das relações étnico-raciais: estudo de caso em uma turma de graduação. Revista da $A B P N$, Uberlândia, v. 10, p. 549-571, maio 2018.

SCHIERHOLT, José Alfredo. Estrela: ontem e hoje. Lajeado, RS: 2002.

SCHUCMAN, Lia Vainer. Branquitude e poder: revisitando o "medo branco" no século XXI. Revista da $A B P N$, Uberlândia, v. 6, n. 13, p. 134-147, mar.jun. 2014.

SILVA, Mozart Linhares da. Educação, etnicidade e preconceito no Brasil. Santa Cruz do Sul: EDUNISC, 2007.

SILVA, Petronilha Beatriz Gonçalves. Ensino de História da África ainda não está nos planos pedagógicos. 2017. Disponível em: <https://www.brasildefato.com.br/2017/01/08/ensino-de-historia-da-africa-ainda-nao-esta-nos-planos-pedagogicos-diz-professora/>. Acesso em: $04 \mathrm{dez} .2017$.

Aprender, ensinar e relações étnico-raciais no Brasil. Educação, Porto Alegre, v. 3, n. 63, p. 489-506, set./dez. 2007.

Pesquisa e luta por reconhecimento e cidadania. In: ABRAMOWICZ, Anete; SILVÉRIO, Valter Roberto (Org.). Afirmando diferenças: montando o quebra-cabeça da diversidade na escola. Campinas: Papirus, 2005. p. 27-54.

SILVA, Tomaz Tadeu da. Documentos de identidade: uma introdução às teorias do currículo. 3. ed. Belo Horizonte: Autêntica, 2014.

SOARES, Claudete Gomes; ANDREOLA, Neuri José. Branquitude e representações sobre imigrantes haitianos no oeste catarinense. Temáticas, Campinas, v. 25, p. 85-114, fev./dez. 2017.

VEIGA-NETO, Alfredo. Dominação, violência, poder e educação escolar em tempos de império. In: RAGO, Margareth; VEIGA-NETO, Alfredo (Org.). Figuras de Foucault. 3. ed. Belo Horizonte: Autêntica, 2013. p. 13-38.

Foucault \& Educação. 3. ed. Belo Horizonte: Autêntica, 2014.

WANDERER, Fernanda. Educação matemática, jogos de linguagem e regulação. São Paulo: Livraria da Física, 2014.

WESCHENFELDER, Viviane. A produção do sujeito negro: uma analítica das verdades que circulam em Venâncio Aires. 2012. 172 f. Dissertação (Mestrado em Educação) - Programa de Pós-Graduação em Educação, Universidade do Vale do Rio dos Sinos, São Leopoldo, 2012. 